\title{
Optimal on-farm irrigation scheduling with a seasonal water limit using simulated annealing
}

\author{
${ }^{1}$ Irrigation Engineer, Aqualinc Research Ltd, PO Box 20-462, Christchurch, New Zealand. E-mail: \\ brownp@aqualinc.co.nz \\ ${ }^{2}$ Senior Lecturer, Dept. of Civil and Natural Resources Engineering, Univ. of Canterbury, Private Bag 4800, \\ Christchurch, New Zealand. E-mail: tom.cochrane@canterbury.ac.nz \\ ${ }^{3}$ Director, Touchwater Ltd, PO Box 143, Lincoln, Christchurch, New Zealand.E-mail: touchwater@gmail.com
}

\section{Abstract}

As water resources are limited and the demand for agricultural products increases, it becomes increasingly important to use irrigation water optimally. At a farm scale, farmer's have a particularly strong incentive to optimize their irrigation water use when the volume of water available over a season is production limiting. In this situation, a farmer's goal is to maximize farm profit, by adjusting when and where irrigation water is used. However, making the very best decisions about when and where to irrigate is not easy, since these daily decisions require consideration of the entire remaining irrigation season. Future rainfall uncertainty further complicates decisions on when and which crops should be subjected to water stress. This paper presents an innovative on-farm irrigation scheduling decision support method called the Canterbury Irrigation Scheduler (CIS) that is suitable when seasonal water availability is limited. Previous optimal scheduling methods generally use stochastic dynamic programming, which requires over-simplistic plant models, limiting their practical usefulness. The CIS method improves on previous methods because it accommodates realistic plant models. Future farm profit (the objective function) is calculated using a time-series simulation model of the farm. Different irrigation management strategies are tested using the farm simulation model. The irrigation strategies are defined by a set of decision variables, and the decision variables are optimized using simulated annealing. The result of this optimization is an irrigation strategy that maximizes the expected future farm profit. This process is repeated several times during the irrigation season using the CIS method, and the optimal irrigation strategy is modified and improved using updated climate and soil moisture information. The ability of the CIS method to produce near optimal decisions was demonstrated by a comparison to previous stochastic dynamic programming schedulers. A second case study shows the CIS method can incorporate more realistic farm models than is possible when using stochastic dynamic programming. This case study used the FarmWi\$e/APSIM model developed by CSIRO, Australia. Results show that when seasonal water limit is the primary constraint on water availability, the CIS could increase pasture yield revenue in Canterbury (New Zealand) in the order of $10 \%$, compared with scheduling irrigation using current state of the art scheduling practice.

Keywords: Irrigation scheduling, optimization, simulated annealing, farm simulation 


\section{Introduction}

2 Making the very best decisions about when and where to irrigate is not easy when irrigation water available over a season is production limiting. Each decision requires consideration of the entire remaining irrigation season. A farmer needs to make difficult decisions about when and which crops will be subjected to water stress. Uncertain rainfall further complicates decisions. Optimal on-farm irrigation scheduling methods can provide advice in these situations.

7 Existing optimal on-farm irrigation schedulers generally use dynamic programming for optimization.

8 A number of authors since the late 1960's have proposed using simplistic plant models combined with dynamic programming optimization to schedule irrigation for a single crop. Bras and Cordova (1981), Rhenals and Bras (1981), and Ramirez and Bras (1985) made significant contributions to these single crop schedulers. They used stochastic dynamic programming (SDP) with a FAO 56/FAO 33 (Doorenbos and Kassam, 1979; Allen et al., 1998) type crop model with a single reservoir of soil moisture (i.e. single soil layer) and single crop-coefficient. They modeled rainfall as both a compound-Poisson process and a Neyman-Scott cluster model, and included a seasonal constraint on water use. Reference evapotranspiration (ET) was modeled both deterministically and stochastically. The authors were unable to show any advantage in modeling rainfall using the more complicated Newman-Scott model compared with the compound-Poisson process, or in modeling reference ET stochastically rather than deterministically.

Rao and Sarma (1990) extended an optimal single crop scheduler, to optimally schedule multiple crops, using a decompositional procedure. Seasonal crop water use versus net return relationships were generated from running a single crop scheduler several times with different seasonal limits - for each crop. Water was then allocated seasonally between different crops, and a weekly schedule generated for each crop. Competition for water between various crops within a given week was constrained by and adjusted for system capacity. Water was optimally allocated for that week, and then the irrigation schedules for each crop were separately optimized from that week until the end of the season; this process was iterative. A similar procedure was used by Sunantara and Ramirez (1997), who extended the single-crop algorithm of Ramirez and Bras (1985) to multiple crops.

All scheduling methods that use SDP must use simplistic crop models such as the FAO33 crop yield model, because SDP requires time independence of all parameters except state variables. Yet, these simplistic crop models are unsuitable for real-world farm profit optimization. For example, in Canterbury, New Zealand, the FAO33 crop yield model performs well under situations of minor to moderate plant water stress, but poorly under severe water stress. Additionally, the SDP method cannot model long irrigator return periods, where very low soil moisture levels stunt pasture growth, which takes several days to recover following irrigation. SDP also cannot account how 1 in 5 or 1 in 10 year droughts often limit land-use capability. 
1 Three optimizing problems closely related to optimal on-farm irrigation scheduling are: (1) optimal

2 real-time scheduling of an open race irrigation distribution system; (2) optimal real-time scheduling

3 from an irrigation reservoir; and (3) optimal pre-season planning of crops and irrigation water

4 allocation.

5 Examples of real-time scheduling of open race irrigation distribution systems include Wardlaw and

6 Barnes' (1999) use of quadratic programming for optimization, Wardlaw and Bhaktikul's (2004) use

7 of a genetic algorithm for optimization, and Monem and Namdarian's (2005) use of simulated

8 annealing for optimization. These methods optimized delivery flows with the aim to minimize

9 distribution losses, and over or under allocation to delivery points, within the capacity constraints of

10 open race delivery systems. Future rainfall and seasonal allocation limits were neglected. An

11 example of real-time scheduling from an irrigation reservoir is Kumar et al.'s (2006) use of a genetic

12 algorithm for optimization. An example of pre-season planning of crops and irrigation water

13 allocation is Georgiou and Papamichail's (2008) use of simulated annealing and a gradient descent

14 algorithm for optimization. Georgiou and Papamichail optimized reservoir release flows to maximize

15 crop yields. Their method accounted for variable reservoir inflows and climate variability, and

16 included a limit on seasonal water availability.

17 All these optimization procedures included at most a simplistic FAO 56/FAO 33 (Doorenbos and 18 Kassam, 1979; Allen et al., 1998) type crop model. For on-farm scheduling, the goal is to maximize 19 farm profit through deciding which and how much particular crops or paddocks will be water stressed, 20 and maximizing the use of rainfall, within the constraints on the available seasonal water and irrigation 21 system capacity. Optimal on-farm irrigation scheduling requires plant models that are realistic under a range of water stress conditions, a factor that is not as important for optimizing open race delivery schedules or reservoir operations. For on-farm scheduling, future climate variability is important because rainfall in semi-arid environments can contribute a significant portion of the soil moisture needs (with the rest being supplemented by irrigation). Neglecting any future rainfall is overly conservative, while assuming average rainfall ignores the risk of drier than average periods.

Many detailed farm system models are now available, capable of modeling complex plant physiological processes. This paper reports on the development of an on-farm optimal irrigation scheduling method that can utilize these detailed models. Given its initial application to the Canterbury region of New Zealand, this method was named the Canterbury irrigation scheduler (CIS).

\section{Method development}

\section{Overview}

The scope of the research was restricted to on-farm irrigation systems that have an on-demand supply, a fixed application depth, and a restriction on the total volume of water available over a season. Given these restrictions, optimal irrigation scheduling requires optimizing decisions about which crops (or 
1 paddocks) if any will be irrigated on each day, between the current day and the end of the irrigation

2 season. The objective is to maximize farm profit $Z^{*}$.

$3 \quad Z^{*}=\max _{\mathbf{I} \in \theta} E\left[p\left(\chi_{n}\right) \forall n=1 \ldots C\right]$

$4 \quad$ Where $Z^{*}=$ maximum expected profit from the current day to the end of the irrigation season; $\mathbf{I}=\left(I_{k} \forall\right.$

$5 k=1 \ldots K)=$ irrigation decisions from the current day to the end of the irrigation season; $K=$ days from

6 the current day to the end of the irrigation season; $I_{k}=$ decision on day $k$ about which crops if any will

7 be irrigated, $\theta=$ set of feasible irrigation decisions; $\chi_{n}=$ future climate scenarios; $C=$ total number of

8 different possible future climate scenarios; $p\left(\chi_{n}\right)=$ farm profit for the remainder of the irrigation

9 season, for future climate instance $\chi_{n}\left(\mathbf{p}=p\left(\chi_{n}\right) \forall n=1 \ldots C\right)$; and $E[]=$ expectation operator. $p\left(\chi_{n}\right)$ is a

10 function of $\mathbf{I}$ and $\mathbf{I}$ is a function of $\chi_{n}$. The function $p\left(\chi_{n}\right)$ is a non-linear and complex function of $\mathbf{I}$

11 because plant physiological response to soil moisture is non-linear and complex, and soil moisture

12 conditions early in the season can impact on plant performance much later in the season. Farm profit

$13\left(p\left(\chi_{n}\right) \forall n=1 \ldots C\right)$ is a stochastic function because the future climate is stochastic and not deterministic.

14 It was assumed function $p\left(\chi_{n}\right)$ could be any farm model (with a time-step of one day or less) that

15 predicts how farm profit is affected by irrigation decisions, simulated from the current day to the end

16 of the irrigation season. $E\left[p\left(\chi_{n}\right) \forall n=1 \ldots C\right]$ was calculated from evaluating $p\left(\chi_{n}\right)$ using several

17 different historical seasons of climate data. Feasible irrigation decisions were constrained by system

18 capacity and seasonal water use limits. The system capacity limits the maximum number of crops that

19 can be irrigated in one day, while the seasonal water use limit restricts the maximum number of

20 irrigation events in a season.

21 Solving Eq. (1) gives a recommendation on how best to manage irrigation, from the current day until 22 the end of the season. This recommendation, however, is only valid for a few days after solving 23 Eq. (1) because the solution to Eq. (1) does not include an exact knowledge of the future climate. 24 After a few days, Eq. (1) should be solved again. Eq. (1) should be solved several times during the irrigation season, each time taking into account updated climate and farm information.

Eq. (1) requires optimization. Mathematical programming techniques cannot solve Eq. (1) because $E[\mathbf{p}]$ is non-linear, complex, and stochastic. Solving Eq. (1) using branch and bound methods would be difficult, if not impossible, because the number of feasible decisions is excessively large. Therefore, given the structure of the problem a "simulated annealing" heuristic method was used for optimization.

\section{Decision variables and constraints}

In order to reduce the number of decision variables to optimize, decision variables described general irrigation strategies rather than individual irrigation decisions (I). Decision variables defined how water use was prioritized in time and space. Prioritization in time was between particular intervals of the irrigation season and prioritization in space was between crops. Specifically, decision variables 
1 describe the expected future water use for each time interval and crop combination (Figure 1). Time

2 intervals, for example, could be months or weeks of the irrigation season. The time interval is

3 different than the time-step in the farm model simulations, which is daily or less. Decision variables

4 are subject to constraints. Irrigation systems are subject to constraints on system capacity - the

5 maximum water which can be applied to a given area per day. System capacity constraints apply at a

6 crop scale and at a farm scale. Irrigation systems may also be subject to a seasonal volume limit. In

7 mathematical form, constraints on Eq. (1) may be approximated as:

$8 \quad 0 \leq a_{i j} \leq \alpha \quad \forall i=1 \ldots T, \forall j=1 \ldots N$

$9 \quad 0 \leq \sum_{j=1}^{N} a_{i j} \leq \beta \quad \forall i=T$

$10 \quad 0 \leq \sum_{i=1}^{T} \sum_{j=1}^{N} a_{i j} \leq \gamma$

11 Where $a_{i j}=$ expected future water use for time interval $i$ and $\operatorname{crop} j\left(\mathbf{A}=a_{i j} \forall i=1 \ldots T, \forall j=1 \ldots N\right) ; \alpha=$

12 crop or paddock irrigation system capacity; $\beta=$ farm irrigation system capacity; $\gamma=$ remaining

13 seasonal water; $T=$ number of time intervals for the remainder of the irrigation season; and $N=$

14 number of crops or paddocks.

\section{[FIGURE 1 ABOUT HERE]}

Constraints Eq. (2b) and Eq. (2c) make it difficult to directly optimize $a_{i j}$. Since Eq. (2b) and Eq. (2c) contain more than one variable in each equation, this creates complicated boundaries in the solution space being optimized, which makes optimization more difficult. Therefore, rather than decision variables directly describing expected future water use, a slightly different definition was used, which avoids inequality constraints containing more than one variable. Eq. (2b) and (2c) were instead replaced with inequality constraints that contain only a single variable, and with linear equality constraints that relate several variables. A modified simulated annealing method (presented later in the paper), together with linear equality constraints, reduced the number of variables that require optimizing simultaneously. The combined effect is a simpler solution space to optimize which therefore increases the efficiency of the algorithm. The following surrogate decision variables $\mathbf{B}, \mathbf{c}$, and $w$ were optimized.

$$
b_{i j}=\frac{a_{i j}}{\sum_{j=1}^{N} a_{i j}} \times \frac{\beta}{\alpha} \quad \forall i=1 \ldots T, \forall j=1 \ldots N \text { and } c_{i}=\frac{1}{\beta} \sum_{j=1}^{N} a_{i j} \quad \forall i=1 \ldots T
$$


$1 \quad 0 \leq b_{i j} \leq 1.0 \quad \forall i=1 \ldots T, \forall j=1 \ldots N$ and $0 \leq c_{i} \leq 1.0 \quad \forall i=1 \ldots T$

$2 \quad \sum_{j=1}^{N} b_{i j}=\frac{\beta}{\alpha} \quad \forall i=1 \ldots T$ and $\sum_{i=1}^{T} c_{i}=\frac{w}{\beta}$

$30 \leq w \leq \gamma$

4 Where $w=$ expected future seasonal water use. $\mathbf{B}=b_{i j} \forall i=1 \ldots T, \forall j=1 \ldots N$ and $\mathbf{c}=c_{i} \forall i=1 \ldots T$.

5 Decision variables $\mathbf{B}$ and $\mathbf{c}$ were optimized using simulated annealing while $w$ can be optimized

6 independently. The optimization problem can be decomposed, where Eq. (1) can be solved for several

7 values of $w$. The profit versus $w$ relationship can then be used to determine the optimal value of $w$.

8 Generally, when water is scarce, it will be advantageous to apply all remaining seasonal water (i.e. $w=$

$9 \gamma$ ). Optimizing $w$ independently improves optimization efficiency. Eq. (3) is a rearrangement of Eq.

10 (2) employing surrogate variables $(\mathbf{B}, \mathbf{c}$, and $w)$, and therefore $\mathbf{B}, \mathbf{c}$, and $w$ indirectly define the

11 expected future water use for each time interval and crop combination and are used as our decision 12 variables.

13 Constraints from Eq. (3b) create boundaries in the solution space; however, these boundaries had only 14 a small effect on optimization efficiency. Decision variables that do not satisfy Eq. (3b) are identified 15 prior to evaluation of the farm simulation (p) in the objective function. This increases optimization 16 efficiency because most of the computational demand is associated with evaluating $\mathbf{p}$ in the objective 17 function.

\section{Relationship between decision variables and an irrigation strategy}

19 An irrigation strategy defined the individual irrigation decisions (I) that are evaluated in the objective function farm simulation (p). An irrigation strategy was a step-wise function (in time) of the trigger soil moisture level, for each crop (Figure 2). Trigger soil moisture levels were adjusted for each evaluation of $p\left(\chi_{n}\right)$ in accordance with the particular possible future climate instance $\left(\chi_{n}\right)$. The trigger soil moisture level is the volumetric soil moisture threshold when irrigation should occur, provided an irrigator is available. Occasionally there will be days when the soil moisture for more than one crop is below the specified trigger soil moisture level, but there is insufficient farm system capacity to irrigate all the crops. Under these circumstances, the crops that have the greatest difference between their current soil moisture status and their trigger soil moisture level were irrigated first. As stated previously, CIS optimizes irrigation strategies and therefore the optimal 'irrigation strategy' will ensure that if scheduling between different crops, a crop with a higher yield value will receive higher priority. 
1 An irrigation strategy was a function of the expected future water use for each time interval and crop

2 combination $(\mathbf{A})$ :

$3 \mathbf{S}=f(\mathbf{A})$

$4 \quad$ Where $\mathbf{S}=\left(s_{i j} \forall i=1 \ldots T, j=1 \ldots N\right)=$ trigger soil moisture level for each time interval $i$ and crop $j$ 5 combination. The inverse of Eq. (4), $\mathbf{A}=f^{-1}(\mathbf{S})$ can be solved using a daily time-step water balance 6 such as CropWat (Smith, 1992), simulated for several seasons, where $a_{i j}$ is simulated average water 7 use for time interval $i$ and crop $j$. Eq. (4) can also be calculated using the same method, by iteratively 8 adjusting $s_{i j}$ until the simulated average water use for time interval $i$ and crop $j=a_{i j}$. However, in this 9 paper, an alternative Markov chain method by Brown (2007) was used to solve Eq. (4). This method was based on Cordova and Bras' (1981) use of Markov chains to describe the influence of climate and irrigation on soil moisture. Brown's method assumed a water balance model, with a single soil layer, and assumed Allen et al.'s (1998) single crop coefficient model. The advantage of Brown's method was it was about two orders of magnitude more computationally efficient than daily time-step water balance simulations.

\section{Objective Function}

16 Figure 3 illustrates the steps of the Canterbury Irrigation Scheduler.

Throughout the course of simulating $p\left(\chi_{n}\right)$ (Figure 3), the expected future water use $\left(a_{i j}\right)$ is adjusted proportionally to the difference between the expected and actual seasonal water remaining. The adjustment was done because of climate uncertainty. The actual water use begins to deviate from the expected water use as the simulation for a particular climate instance $\chi_{n}$ progresses. If no adjustment to the irrigation strategy is made, either the available water for the season is used up prematurely or there is excess water at the end of the season. To reduce the computational demand, adjustments to an irrigation strategy (S) when simulating $p\left(\chi_{n}\right)$ were made at the start of each time interval rather than daily (using Eq. (3a) and (4)). At the end of simulating $p\left(\chi_{n}\right)$, farm profit was calculated from the simulation outputs.

\section{Optimization}

The simulated annealing method for continuous variables by Press et al. (2002) is a modification of Nelder and Mead's (1965) downhill simplex method. The method was adapted for use with the irrigation scheduler in Figure 3 because it offered the following advantages:

a) Optimization is in continuous space, taking full advantage of solution space gradients. 
b) It is robust for extreme gradients and discontinuities. This allows inequality boundary conditions, Eq. (3b), to be incorporated using a penalty term to discourage exploration of infeasible parts of the solution space.

c) Greater exploration occurs in dimensions where an optimum value for a particular decision variable is highly dependent on the value of other decision variables, and less exploration when a decision variable is relatively independent of other decision variables. This is because the simplex contracts in the dimensions where decision variables within a narrow range generally result in better objective function performance.

d) The region inside the simplex (rather than a single trajectory) is sampled with each simplex move.

Press et al.'s method was modified to allow for Eq. (3c) linear equality constraints. The number of simplex vertices was reduced by the number of equality constraints, and vertices of the initialization simplex were chosen so they satisfied Eq. (3c). As long as all the starting points of Nelder Mead's simplex satisfy linear equality constraints, all subsequent simplex moves will also satisfy these equalities. This is because all new simplex vertices are linear combinations of existing vertices. In addition to not requiring any penalty functions to enforce constraints from Eq. (3c), the number of dimensions of the solution space being optimized is reduced by the number of constraints because an equality constraint mathematically represents a reduction in a degree of freedom.

\section{Case study 1: Canterbury Irrigation Scheduler and a SDP scheduler}

The CIS's performance was compared against optimum solutions to: (1) test assumptions associated with optimizing irrigation strategies rather than directly optimizing individual irrigation event decisions and; (2) test the performance of the CIS's simulated annealing optimizer. The CIS performance was compared to a SDP irrigation scheduler because SDP schedulers such as Bras and Cordova's (1981) algorithm can guarantee an optimum solution (although the objective function being optimized is too simple for these solutions to be applicable in practice). SDP schedulers also directly optimize individual (daily) irrigation decisions, and therefore avoid assumptions associated with optimizing general irrigation strategies.

The SDP method used was a variant of Bras and Cordova's (1981) single crop algorithm. Their algorithm was extended to schedule between multiple crops using standard SDP. Each additional crop requires an additional state variable, and therefore computational demand increased exponentially with each additional crop.

Two typical crops in Canterbury were modeled - pasture and wheat. Pasture was modeled as a perennial crop with a constant rooting depth and an ET crop coefficient of 1.0. Wheat was modeled with varying crop coefficients and rooting depths. Wheat parameters were obtained from Allen et al. (1998), and modified according to typical summer planting and harvesting dates for Canterbury, New Zealand (Figure 4). Rainfall time-series were synthetically generated using a compound-Poisson 
model; while the annual reference ET time-series was assumed to be the mean of the historic values, as a function of the time of year. Model parameters were derived from historic Christchurch airport data, for the period 1960 to 2004. Synthetic, rather than historic, climate data was used in both the case study and objective function farm model time-series simulations $\left(p\left(\chi_{n}\right) \forall n=1 \ldots C\right)$ so that the climate assumptions (stochastic rainfall with a compound-Poisson process and deterministic ET) embedded within the SDP formulation would be exactly true. Ten seasons were simulated for each objective function evaluation (i.e. $C=10$ ). System capacity was constrained so only one paddock could be irrigated on a given day for this case study (CIS allows for more than one paddock to be irrigated on a given day if necessary). Irrigator application depth and seasonal water use limits (Table 1) were chosen so that seasonal limits were always constraining (i.e. required deficit irrigation), and so that system capacity was constraining for two or more paddocks. A paddock area of 10 ha was assumed; therefore $1 \mathrm{~mm}$ of applied water per paddock corresponds to $100 \mathrm{~m}^{3}$. Four case studies were run: (1) A single paddock of pasture; (2) A single paddock of wheat; (3) A paddock of pasture and wheat; and (4) Three paddocks of pasture. Parameters for these four case studies are given in Table 1. The CIS's simulated annealing initial temperature was $50 \%$ of the experimental standard deviation of the solution space being optimized; and was calculated by random sampling. The simulated annealing regime comprised of 6 linearly reducing temperature steps, with the number of simplex moves per temperature step equal to $50 \times T \times N-1$.

[FIGURE 4 ABOUT HERE]

The irrigation season for wheat began two days before planting and ended at grain ripening. Two different irrigation seasons were used for pasture. The first, 15 September to 29 March, is a typical season given moderate seasonal water use limits. The second, 1 November to 20 February, was used for the three-paddock case study in order to make the SDP algorithm computationally feasible. Such a short season could be encountered in Canterbury if seasonal water limits were very low. Time intervals, which divided up the irrigation season, were four weeks long when all paddocks were pasture and two weeks long when one or more of the paddocks was wheat. Potential ET and plant total available water at field capacity (TAW) were functions of time. Within both the CIS and SDP schedulers, these two functions were approximated step-wise in time, with the width of a step equal to the time interval. Wheat's PET and TAW are more variable in time than say pasture, so it is necessary to use shorter management periods in the optimization. We have used 2 weeks.

Potential yield values $\left(y_{p}\right)$ were $\$ 3,900 /$ ha for pasture and $\$ 5,300 /$ ha for wheat. Doorenbos and Kassam's (1979) yield reduction factor $\left(k_{y}\right)$ for both pasture and wheat was assumed to have a constant value of 1.0 throughout the irrigation season. The cost function $(y)$ to be optimized was: 
$1 \quad y=\sum_{j=1}^{N}\left(y_{p} \sum_{t=1}^{L}\left(k_{y} \frac{e_{a}}{e_{p}}\right)\right)-\Psi \mu$

2 Where $N=$ number of paddocks; $t=$ day of the irrigation season; $L=$ length of the irrigation season

3 (days); $e_{p}=$ potential ET (varying with time); and $e_{a}=$ actual ET (varying with time, rainfall, and 4 irrigation decisions); $\Psi=$ unit cost of irrigation water; and $\mu=$ irrigation water use.

5 The resulting yield returns for irrigation scheduling using SDP, the CIS, and best management 6 practice, for the four case studies, are presented in Figure 5. For each of the case studies, 10 years were simulated (which were different from the 10 seasons $(\chi)$ used in the objective function of the CIS). Best management practice aimed to model current state of the art scheduling advice, typical of the advice an extension service may offer. Specifically, best management practice scheduled irrigation so that the expected trigger soil moisture level was constant for the remainder of the season, with advice regularly updated during the season in response to the climate.

\section{[FIGURE 5 ABOUT HERE]}

Figure 5 shows that, for any given case study season, the particular scheduling method that resulted in the greatest yield value was probabilistic. Generally, the CIS and SDP schedulers resulted in comparable performance, and these two methods out-perform best management practice. However, occasionally, the best management practice method would result in the greatest yield value. This observation was expected, since both the SDP and the CIS seek to optimize the expected future yield return. However actual performance for a given season is probabilistic, due to the unknown [stochastic] future climate. The mean difference (compared with SDP scheduling) averaged over all case studies for the CIS was $-0.2 \%$ (null hypothesis: identical pop. means, $P>0.3$, paired t test, sample size 40 ) and for best management practice was $-6.0 \%$ (null hypothesis: identical pop. means, $P$ $<0.005$, paired $t$ test, sample size 40). Therefore, it was concluded that the CIS and the SDP scheduling methods had near identical mean performance, while scheduling using best management practice resulted in inferior mean performance. Since the CIS was able to closely match the performance of SDP, assumptions associated with optimizing irrigation strategies rather than directly optimizing individual irrigation event decisions appear reasonable, and the CIS can (in at least simplistic cases such as Case Study 1) produce close to optimal schedules.

\section{Case study 2: The Canterbury Irrigation Scheduler with a detailed farm} simulation

A second case study demonstrated that the CIS can use detailed farm system models in the objective function $\left(p\left(\chi_{n}\right)\right)$. The FarmWi\$e/APSIM model by CSIRO, Australia, was used. operations. CSIRO common modeling protocol framework allows for the addition and/or interchange 
1 of model components. In particular, a partnership with the (Australian) Agricultural Production

2 Systems Research Unit has made cropping models associated with the APSIM framework available.

3 As a result FarmWi\$e has the capacity to model a wide range of farming operations including

4 dairying, sheep and beef, and mixed cropping (Donnelly et al., 2002).

5 The FarmWi\$e model has been built as a collection of inter-changeable components which 6 communicate with one another via a set of defined messages. This allows any component which 7 conforms to CSIRO's common modeling protocol to be used in FarmWi\$e. The CIS and best 8 management practice irrigation scheduling methods were implemented within FarmWi\$e by such a 9 custom common modeling protocol component.

The case study farm operation was growing and cutting grass (e.g. for dairy support) for a single paddock. Although scheduling with a detailed farm system model can also be done between multiple crops or paddocks, in this paper only a single paddock was used to limit the computational demand. The case study farm consisted of soil, pasture, climate, and farm management components, as described by Brown (2007) and summarized in Table 2. Climate data was for Christchurch airport, New Zealand. While the soil component allows for multiple soil layers, only a single layer was assumed, again to limit the computational demand. The reason for this was to increase the agreement between Brown's (2007) Markov chain method used to solve Eq. (4) (that assumes a single-soil layer but is more computationally efficient than the daily water balance solution to Eq. (4)) and the FarmWi\$e irrigation water use model.

\section{[TABLE 2 ABOUT HERE]}

Five seasons of historical climate were used for the case study and five different seasons of historical climate were used within the objective function $\left(p\left(\chi_{n}\right) \forall i=1 \ldots 5\right)$. Pasture was cut when the total cover exceeded 4,000 kg-DM (dry matter)/ha, down to $1,500 \mathrm{~kg}-\mathrm{DM} / \mathrm{ha}$. The cost function $(y)$ was optimized.

$y=v \times(q-0.5) / 0.5 \times 0.40 \$ /(\mathrm{kg}-\mathrm{DM} / \mathrm{ha})-0.1\left(\$ / \mathrm{m}^{3}\right) \times \mu$

Where $v=$ pasture quantity (kg-DM/ha); $q=$ pasture quality ( $\%$ of DM digestibility); and $\mu=$ irrigation water use $\left(\mathrm{m}^{3}\right)$. Below a DM digestibility of 0.5 , it was assumed that the pasture had no value but instead would incur a cost associated with harvesting the grass. From Eq. (6), the value of pasture will generally be in the range of $0.08-0.24 \$ / \mathrm{kg}$-DM per ha (for a DM digestibility of 0.6-0.8, respectively). These prices are reasonable for dairy support in Canterbury, New Zealand. Eq, (6) assumes the yield value is deterministic. When making decisions for a single irrigation season this should be an acceptable approach. The method could allow for the yield value to be a stochastic variable, using a Monte Carlo approach, provided an increased number of seasons $(C)$ are simulated in the objective function. 
1 A fixed irrigation application depth of $15 \mathrm{~mm}$ was assumed. Scheduling irrigation using the CIS was compared with a best management practice methodology - which managed irrigation so the expected trigger soil moisture level was constant for the remainder of the season, with advice regularly updated during the season in response to the climate. The irrigation season was from 15 September to 4 April and the season was divided in time intervals of 50 days long. The seasonal water limit was $390 \mathrm{~mm} / \mathrm{ha}$ per year. Figure 6 presents the annual yield returns, given the two different irrigation scheduling methods.

A rapid simulated annealing cooling regime was used to limit the number of objective function evaluations within the CIS. The annealing regime comprised of three (linearly reducing) temperature steps, with the number of simplex moves per temperature step equal to $20 \times T-1$. The initial annealing temperate was 0.6 times the standard deviation of a random sample of the solution space being optimized. Altogether about 180 evaluations of the objective function were required each time Eq. (1) was solved. Despite the rapid annealing cooling, the optimizer still converged to a minima, which was significantly better than solutions found from random sampling.

Figure 6 shows that using the CIS resulted in significantly greater yield returns, compared with best management practice, in four out of the five case study seasons. In the fifth season, both scheduling methods resulted in comparable returns. The lack of any advantage in scheduling using the CIS for the 2001 case study season was because the CIS method was intended for deficit irrigation problems and in this case the seasonal water limit was in excess of that required to provide full irrigation. Although the available seasonal water was sufficient for full irrigation in the 2001 season, yields were less than the 1971 and 1991 seasons, because factors other than water stress (e.g. temperature and solar radiation) affect crop yields. The average yield return, for the five case study seasons, was $8.9 \%$ higher using scheduling determined by CIS compared to best management practice (null hypothesis: identical pop. means, $P<0.02$, paired t test, sample size 5 ). Therefore, it was concluded that the CIS had superior performance compared with using best management practice.

\section{Conclusions}

A novel optimal multi-crop irrigation scheduling algorithm was developed which was able to incorporate detailed farm system models, and constraints on daily and seasonal water use, with the objective of maximizing farm profit. The key features of this CIS were:

a) Use of a detailed farm time-series simulation in the objective function, to model the response of farm profit to irrigation decisions;

b) Incorporation of climate stochastic characteristics in the objective function through time-series simulation of multiple seasons; 
1 c) Optimization of decision variables which describe general irrigation strategies rather than directly optimizing individual irrigation events;

3 d) Use of downhill simplex simulated annealing for optimization, modified to incorporate water use constraints.

5 A comparison between this method and stochastic dynamic programming schedulers demonstrated 6 that this algorithm was able to produce close to optimal schedules. A second case study which used 7 the FarmWi\$e model demonstrated the ability of this method to incorporate detailed farm system 8 models, and the ability of the CIS to increase the value of pastoral yield in Canterbury, New Zealand, 9 in the order of $10 \%$, on farms where a seasonal water limit is the primary constraint on water availability.

11 Further work is required to apply and validate the CIS's performance with more realistic farm systems 12 that include multiple paddocks, multi-layered soils, and livestock models. The CIS method is already 13 adapted to schedule for multiple paddocks; however, computation demands are high because longer annealing times are required for convergence and each farm simulation takes longer to evaluate. The method can also include multi-layer soils in the objective function if Eq. (4) is solved iteratively by running a daily time-step water balance multiple times, rather than using a Markov Chain. This alternate solution to Eq. (4) also has higher computational demands.

Although high computational demands can be a current disadvantage of the CIS method when including multiple paddocks and multi-layered soils, improvements in code efficiency (i.e. parallel computing) or raw computing speed will undoubtedly overcome this deficiency. It is worth noting, however, that the CIS will only be of practical use in situations where the value of water is high enough to justify the time and cost associated with a farmer maintaining a farm system computer model. Future applications of the CIS method could be expanded to include horticultural crop models.

\section{Summary of notation}

\section{Symbols}

$\mathbf{I}=\left(I_{k} \forall k=1 \ldots K\right)=$ irrigation control policy from the current day to the end of the irrigation season.

$K=$ days from the current day to the end of the irrigation season.

$I_{k}=$ decision on day $k$ about which crops if any will be irrigated.

$\theta=$ set of feasible irrigation control policies.

$\mathbf{p}=\left(p\left(\chi_{n}\right) \forall n=1 \ldots C\right)=$ farm profit for the remainder of the irrigation season, for each $\chi_{n}$.

$\chi=\left(\chi_{n} \forall n=1 \ldots C\right)=$ possible future climate scenarios.

$32 Z^{*}=$ maximum expected profit from the current day to the end of the irrigation season

$33 C=$ total number of different possible future climate scenarios. 
$1 E[]=$ expectation operator.

$2 \quad \mathbf{A}=\left(a_{i j} \forall i=1 \ldots T, \forall j=1 \ldots N\right)=$ expected future water use for each time interval $i$ and crop $j$.

$3 T=$ number of time intervals for the remainder of the irrigation season.

$4 \quad N=$ number of crops or paddocks.

$5 \quad \alpha=$ crop or paddock irrigation system capacity.

$6 \beta=$ farm irrigation system capacity.

$7 \gamma=$ remaining seasonal water.

$8 w=$ expected future seasonal water use.

$9 \quad \mathbf{B}\left(=b_{i j} \forall i=1 \ldots T, \forall j=1 \ldots N\right), \mathbf{c}\left(=c_{i} \forall i=1 \ldots T\right)$, and $w=$ optimization decision variables.

$10 \mathrm{~S}=\left(s_{i j} \forall i=1 \ldots T, j=1 \ldots N\right)=$ trigger soil moisture level for each time interval $i$ and crop $j$ 11 combination (irrigation strategy).

$12 t=$ day of the irrigation season.

$13 L=$ length of irrigation season (days).

$14 e_{p}=$ potential evapotranspiration.

$15 e_{a}=$ actual evapotranspiration.

$16 k_{y}=$ yield reduction factor

$17 v=$ pasture yield (kg of dry matter per hectare).

$18 q=$ pasture quality ( $\%$ of dry matter digestibility).

$19 \Psi=$ unit cost of irrigation water $\left(\$ / \mathrm{m}^{3}\right)$.

$20 \mu=$ irrigation water use $\left(\mathrm{m}^{3}\right)$.

$21 y_{p}=$ potential yield value.

$22 y=$ cost function.

\section{Acronyms}

$24 \mathrm{DM}=$ dry matter.

25 ET = evapotranspiration.

26 CIS $=$ Canterbury Irrigation Scheduler.

27 SDP $=$ stochastic dynamic programming.

28 TAW = volumetric total soil plant available water at field capacity in millimeters.

\section{Acknowledgements}

30 Research funding from the Foundation of Science, Research, and Technology (contract ID LVLX0302 and LVLX0303) is gratefully acknowledged.

\section{References}

Allen, R. G., Pereira, L. S., Raes, D., Smith, M., 1998. Crop evapotranspiration: Guidelines for computing crop water requirements. FAO Irrig. and Drain. Paper No. 56. Rome. 
1 Bras, R. L., Cordova, J. R., 1981. Intraseasonal water allocation in deficit irrigation. Water Resour. Res. 17(4) 866-874.

3 4

Brown, P. D., 2007. Optimal irrigation scheduling. Ph.D. thesis, Univ. of Canterbury, Christchurch, NZ.

Cordova, J. R., Bras, R. L., 1981. Physically based probabilistic models of infiltration, soil moisture, and actual evapotranspiration. Water Resour. Res. 17(1) 93-106.

Donnelly, J. R., Freer, M., Salmon, L., Moore, A. D., Simpson, R. J., Dove, H., Bolger, T. P., 2002. Evolution of the GRAZPLAN decision support tools and adoption by the grazing industry in temperate Australia. Agric. Systems 74(1) 115-139.

Doorenbos, J., Kassam, A. H., 1979. Yield response to water. FAO Irrig. and Drain. Paper No. 33. Rome.

Kumar, D. N., Raju, K. S., Ashok, B., 2006. Optimal reservoir operation for irrigation of multiple crops using genetic algorithms. J. Irrig. and Drain. 132(2): 123-129.

Moore, A. D., J. R. Donnelly, Freer., M., 1997. GRAZPLAN: Decision support systems for Australian grazing enterprises. III. Pasture growth and soil moisture submodels, and the GrassGro DSS. Agricultural Systems 55: 535-582.

Monem, M. J., Namdarian, R., 2005. Application of simulated annealing (SA) techniques for optimal water distribution in irrigation canals. Irrig. and Drain. 54: 365-373.

Nelder, J. A., Mead, R., 1965. A simplex method for function minimization. Comp. J. 7(4) 308-313.

Georgiou, P. E., Papamichail, D. M., 2008. Optimization model of an irrigation reservoir for water allocation and crop planning under various weather conditions. Irrig. Sci. 26: 487-504.

Press, W. H., Teukolsky, S. A., Vetterling, W. T., Flannery, B. P., 2002. Numerical recipes in C++ : the art of scientific computing. Cambridge Univ. Press, New York.

Rao, N. H., Sarma, P. B. S., 1990. Optimal multicrop allocation of seasonal and intraseasonal irrigation water. Water Resour. Res. 26(4) 551-559.

Ramirez, J. A. Bras, R. L., 1985. Conditional distributions of Neyman-Scott models for storm arrivals and their use in irrigation scheduling. Water Resour. Res. 21(3) 317-330.

Rhenals, A., Bras, R. L., 1981. The irrigation scheduling problem and evapotranspiration uncertainty. Water Resour. Res. 17(5) 1328-1338. 
1 Smith, M., 1992. CROPWAT - A computer program for irrigation planning and management. FAO Irrig. and Drain. Paper No. 46. Rome.

3 Sunantara, J. D., Ramirez, J. A., 1997. Optimal stochastic multicrop seasonal and intraseasonal irrigation control. J. Water Resour. Planning and Manage. 123(1) 39-48.

5 Wardlaw, R., J. Barnes., 1999. Optimal allocation of irrigation water supplies in real time. J. Irrig. and 6 Drain. 125(6) 345-354.

7 Wardlaw, R., Bhaktikul, K., 2004. Application of genetic algorithms for irrigation water scheduling. Irrig. and Drain. 53(4) 397-414. 


\section{Tables}

2 Table 1. Case study parameters for the comparison between the CIS and SDP scheduler.

\begin{tabular}{|c|c|c|c|c|}
\hline Parameter & Case study 1a & Case study $1 b$ & Case study $1 \mathrm{c}$ & Case study $1 \mathrm{~d}$ \\
\hline $\begin{array}{l}\text { Paddock description and Max. } \\
\text { soil plant available water at } \\
\text { field capacity (in mm) }\end{array}$ & $1 \times$ Pasture $(80)$ & $1 \times$ Wheat $(120)$ & $\begin{array}{l}1 \times \text { Pasture }(80) \\
1 \times \text { Wheat }(120)\end{array}$ & $\begin{array}{l}1 \times \text { Pasture }(40) \\
1 \times \text { Pasture }(50) \\
1 \times \text { Pasture }(60)\end{array}$ \\
\hline Irrigation depth (mm) & 15 & 15 & 8 & 12 \\
\hline Seasonal water limit $\left(100 \mathrm{~m}^{3}\right)$ & 300 & 180 & 480 & 900 \\
\hline $\begin{array}{l}\text { Irrigation season (note: } \\
\text { southern hemisphere) }\end{array}$ & 15 Sep-29 Mar & 29 Sep-15 Feb & 29 Sep-15 Feb & 1 Nov-20 Feb \\
\hline Irrig. season duration (days) & 196 & 140 & 140 & 112 \\
\hline Length of time intervals (days) & 28 & 14 & 14 & 28 \\
\hline Unit cost of water $\left(\$ / \mathrm{m}^{3}\right)$ & 0.1 & 0.1 & 0.1 & 0.1 \\
\hline
\end{tabular}

3

4 Table 2. FarmWi\$e soil and pasture model parameters

\begin{tabular}{lccc}
\hline Parameter & \multicolumn{1}{c}{ Value } & Parameter & Value \\
\hline \multicolumn{1}{c}{ SOIL COMPONENT } & \\
\hline Single soil layer thickness & $600 \mathrm{~mm}$ & Saturated hydraulic conductivity & $500 \mathrm{~mm} / \mathrm{d}$ \\
\hline Water content at saturation & $0.47 \mathrm{~mm} / \mathrm{mm}$ & Clay content & $20 \%$ \\
\hline Water content at field capacity & $0.25 \mathrm{~mm} / \mathrm{mm}$ & Sand content & $70 \%$ \\
\hline Water content at wilting point & $0.10 \mathrm{~mm} / \mathrm{mm}$ & Soil albedo & 0.17 \\
\hline Bulk density & $1.3 \mathrm{Mg} \cdot \mathrm{m}^{-3}$ & $\begin{array}{l}\text { Evaporation rate parameter } \alpha \\
\text { (Moore et al. (1997), Table 10) }\end{array}$ & $3.5 \mathrm{~mm} \cdot \mathrm{d}^{-0.5}$ \\
\hline & \multicolumn{2}{c}{ PASTURE COMPONENT } & High \\
\hline Plant species & Perennial ryegrass & Soil fertility & Default values for \\
\hline Rooting depth & $600 \mathrm{~mm}$ & Other plant parameters & perennial ryegrass \\
\hline
\end{tabular}

5

\section{$6 \quad$ Figure captions}

7 Fig. 1. Irrigation scheduling is expressed as an allocation problem, where a limited resource (expected future water use) is optimally allocated between each time interval and crop combination $\left(a_{i j}\right)$, subject to a seasonal water use limit, and farm and crop irrigation system capacity constraints.

Fig. 2. An irrigation strategy is defined by a trigger soil moisture level, which is a step-wise function in time. An irrigation strategy dictates individual irrigation events. An irrigation strategy for a farm contains a trigger soil moisture level function for each crop or paddock.

Fig. 3. The Canterbury Irrigation Scheduler flow chart. 
1 Fig. 4. Crop coefficient $\left(k_{c}\right)$ and soil moisture storage (TAW/max.TAW) series for wheat. TAW $=$ total volumetric soil plant available water at field capacity.

3

[FIGURE 5a HERE]

[FIGURE 5b HERE]

Case study 1a - Single paddock of pasture Case study $1 \mathrm{~b}$ - Single paddock of wheat

[FIGURE 5c HERE] [FIGURE 5d HERE]

Case study $1 \mathrm{c}-$ Paddock of wheat and pasture Case study $1 \mathrm{~d}$ - Three paddocks of pasture

4 Fig. 5. Yield returns for irrigation scheduling using SDP, the CIS, and best management practice, for 5 4 case studies.

6

$7 \quad$ Fig. 6. Comparison of annual yield returns as simulated by FarmWi\$e with irrigation scheduling 8 using the CIS and best management practice. 